\title{
Isolation, Identification, Molecular Characterization and Antibiogram of E. coli Isolates from Neonatal Calves
}

\author{
Shailendri Gupta ${ }^{1 *}$, Abhishek ${ }^{1}$, Sameer Shrivastava ${ }^{2}$ and Asha K. Verma ${ }^{3}$ \\ ${ }^{1}$ Division of Bacteriology \& Mycology, ICAR-IVRI, Izatnagar-243122, India \\ ${ }^{2}$ Division of Veterinary Biotechnology, ICAR-IVRI, Izatnagar-243122, India \\ ${ }^{3}$ Division of Veterinary Public Health, ICAR-IVRI, Izatnagar-243122, India \\ *Corresponding author
}

\begin{abstract}
A B S T R A C T
Keywords

Neonatal calf diarrhoea (NCD), multidrug resistant MDR E. coli, uspA gene, Antibiogram, Carbapenem Resistant, ESBL Producers

Article Info

Accepted:

15 May 2019

Available Online:

10 June 2019

Neonatal calf diarrhoea (NCD) is a major threat to dairy industries. It is a multi-etiology disease with $E$. coli as the predominant cause. Emergence of antimicrobial resistance is of utmost concern because it has rendered the present day antibiotics less effective. The present study aims for isolation, molecular characterization and antimicrobial resistant profiling of $E$. coli from neonatal calves. One hundred two fecal samples were collected from neonatal calves for isolation of E. coli. All the isolates showed positive result on biochemical analysis. But only $78.43 \%$ (80/102) of them were found positive for uspA (universal stress protein) gene. The nucleotide sequences flanking the gene encoding the $u s p \mathrm{~A}$ and was found to be highly specific for $E$. coli. The antibiogram of $E$. coli isolates by Kirby Bauer disc diffusion method revealed highest resistance against kanamycin (97\%) and lowest against gentamicin (5.86\%). Eighty three percent (85/102) isolates were MDR. $39(38.24 \%)$ isolates were phenotypic ESBL producers (by combination disc diffusion method) and 22 (21.57\%) isolates were phenotypic carbapenem resistant (against Ertapenem, Meropenem, Imipenem, Doripenam) Hence, surveillance based study and search for an alternative to antibiotics is needed to address the global issue of the antimicrobial resistance.
\end{abstract}

\section{Introduction}

Sustainable livestock production depends on the successful raising of healthy neonates (Muktar et al., 2015). Neonatal diseases and mortality among the cattle and buffalo calves are the major cause of economic losses in livestock production (Singh et al., 2009). It has been estimated that $75 \%$ of early calf mortality in dairy herds is due to acute diarrhea during the pre-weaning period
(Blowey, 1990). Diarrhea in neonatal calves is a complex, multi-factorial and most dynamic disease (Lorenz et al., 2011). Typical calf diarrhea outbreaks often involve mixed infections of virus, bacteria and other agents which are a potent source of zoonosis. The most important group of bacteria causing calf diarrhea are E. coli, Salmonella and Clostridium perfringens. E. coli is the predominant aerobic organism in the normal intestinal microbiota of mammals and plays 
an important role in host metabolism, immunology and nutrition (Tenaillon et al., 2010). It enhances digestion process and helps in nutrient assimilation. But in debilitated or immunosuppressed host or when gastrointestinal barriers are violated, even normal non-pathogenic strains of $E$. coli can cause infection. Pathogenic E. coli is one of the most common groups of bacteria causing diarrhea and extra intestinal infections in both animals and human (Levine, 1987). Escherichia coli has six usp genes namely A, $\mathrm{C}, \mathrm{D}, \mathrm{E}, \mathrm{F}$ and $\mathrm{G}$, and the usp $\mathrm{A}$ gene is important for the survival of $E$. coli during cellular growth, adhesion and motility (Nachin et al., 2005). Synthesis of usp protein is induced in response to stress such as starvation, heat shock, presence of toxins or osmotic pressure (Nyström and Neidhardt, 1992), however, cold shock doesn't induce synthesis of uspA (Nyström and Neidhardt, 1993).

Rise of Multi-Drug Resistant (MDR) microbes in early 1960s was a major setback for the antibiotics industry. These MDRs are taking us back to the pre-antibiotic era where minor infections and injury was fatal. E. coli serves as a sentinel organism for antimicrobial resistance development in various animals (Allen et al., 2010).

It is an enteric commensal, can be a pathogen, and easily acquires resistance. It can play a role in transfer of resistance to other species or pathogens (Aarestrup et al., 1999; Stobberingh and Bogaard et al., 2000; Allen et al., 2010; Ashbolt et al., 2013). This inevitable process of development antimicrobial resistance could be slowed down only by judicious use of appropriate antibiotics. Hence, surveillance based study, antimicrobial resistance profiling and search for an alternative to antibiotics is the need of hour to address the global issue of the antimicrobial resistance. In this study, isolation, biochemical analysis, molecular characterization by usp A gene and antibiotic resistance profiling of $102 \mathrm{E}$. coli isolates from neonatal calves was done.

\section{Material and Methods}

\section{Sample collection}

Fecal samples of neonatal calves of cattle and buffalo were collected from Cattle and Buffalo Farm, Livestock Product Management section, IVRI, Izatnagar. Basic information about the dairy farm and management was taken. A total of 102 fecal samples including 14 diarrhoeic samples were collected from calves of cattle (Vrindavani and Tharparkar) and buffalo (Murrah) of below 3 months of age. Sterile fecal swabs (Hi-media, India) were used for sample collection. All the samples were transported immediately to the laboratory under cold chain and were processed for isolation of $E$. coli using standard microbiological techniques.

\section{Bacterial isolation}

\section{Enrichment media}

For isolation of E.coli, a loopful of fecal sample was enriched in BPW (Buffered Peptone Water), and incubated at $37{ }^{\circ} \mathrm{C}$ for 16-18 hours.

\section{Selective media}

Enriched culture was inoculated into MacConkey's agar and incubated at $37{ }^{\circ} \mathrm{C}$ for 18-24 hours.

\section{Differential media}

Pink colour colonies on MacConkey's agar were selectively picked and streaked aseptically onto Eosin Methylene Blue (EMB) 
agar and incubated at $37^{\circ} \mathrm{C}$ for $18-24$ hours. The isolates showing atypically colonies were once again streaked on fresh EMB plates.

\section{Identification of $E$. coli}

\section{Gram's staining}

Partially identified cultures were suspended in normal saline and smeared over a slide. The smears were allowed to air dry followed by heat fixing and Gram's staining.

\section{Molecular characterization}

\section{DNA extraction}

The bacteria grown for $18 \mathrm{hr}$ in LB broth were pelleted in $1.5 \mathrm{ml}$ micro centrifuge tube by centrifugation for $10 \mathrm{~min}$ at $5000 \mathrm{x} g$ (7500 rpm). The genomic DNA of the isolates was extracted by using QIAamp DNA Mini Kit (Qiagen, USA) following the manufacturer's protocol.

\section{PCR confirmation}

All the biochemically confirmed isolates where subjected to PCR for the presence of uspA gene (884bp). Species specific primers (F-5'-CCGATACGCTGCCAATCAGT-3'

and R-5'-ACGCAGACCGTAAGGGCCA GAT-3') were used to amplify the uspA genes of E. coli (Osek, 2001; Rajput et al., 2014) which was procured from Eurofins Genomics India Pvt. Ltd., Bengaluru. PCR reaction was performed in a volume of $25 \mu 1$ containing 1.5 units of Taq DNA polymerase, $1.5 \mathrm{mM}$ $\mathrm{MgCl}_{2}, 200 \mu \mathrm{M}$ of each deoxynucleoside triphosphate, 10 pmol of each primer, $50 \mathrm{ng}$ of template DNA and nuclease free water up to $25 \mu \mathrm{l}$. PCR conditions are mentioned in table1 (Mishra et. al. 2017). The amplified PCR products $(10 \mu \mathrm{l}$ aliquots) were analyzed by electrophoresis in $1.5 \%$ agarose gels in tris acetate EDTA buffer at $100 \mathrm{~V}$. The gels were stained with ethidium bromide and viewed under ultraviolet light using a commercial documentation system (Alpha Innotech, USA).

\section{Biochemical characterization}

All Gram negative culture were subjected to biochemical characterization by using a HilMViC kit which consists of combination of 12 tests; four conventional biochemical tests and eight carbohydrate utilization tests. Kit contained sterile media for indole, methyl red, Voges Proskauer's, citrate utilization tests and 8 different carbohydrates i.e. glucose, adonitol, arabinose, lactose, sorbitol, mannitol, rhamnose and sucrose.

The standard test procedure mentioned in the kit was followed. The results were interpreted as per the standards given in the interpretation chart provided by the manufacture of the kit. E. coli reference strains available at National Salmonella Centre, IVRI were used as positive control for biochemical identification.

\section{Antimicrobial resistance profiling}

\section{Antibiogram}

The detailed antibiogram of $E$. coli isolates was determined by against 16 antibiotics belonging to 8 different classes by Kirby Bauer disc diffusion method (CLSI, 2015). Disc used were Aminoglycosides

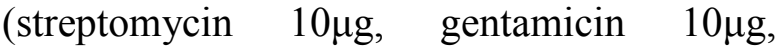
kanamycin 30 $\mu \mathrm{g}$, amikacin 30g) Polymyxin

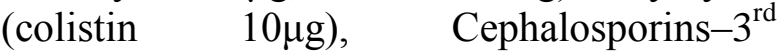
generation (cefotaxime $30 \mu \mathrm{g}$, ceftazidime

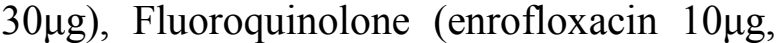
ciprofloxacin $5 \mu \mathrm{g}$, ofloxacin $5 \mu \mathrm{g}$ ), Penicillins $\left.\begin{array}{lll}\text { (ampicillin } & 10 & \mu \mathrm{g}\end{array}\right), \quad$ Tetracyclines (tetracyclines $30 \mu \mathrm{g}$ ), Sulphonamides (cotrimoxazole $25 \mu \mathrm{g}$, sulphadiazine $100 \mu \mathrm{g}$ ), nitrofurantoin $30 \mu \mathrm{g}$ and trimethoprim. 
The E. coli isolates were grown in $5 \mathrm{ml} \mathrm{LB}$ broth (BD, BBL Difco, USA) at $37^{\circ} \mathrm{C}$ for $8 \mathrm{hr}$ to develop a turbidity of 0.5 McFarland standards. Uniform bacterial lawn was prepared on sterile Mueller Hinton Agar (MHA BD, BBL Difco, USA) plates surface with the help of cotton swab using aseptic technique. The antibiotic discs were placed on MHA with adequate spacing between each other with sterilized forceps. The discs were gently pressed to ensure full contact with the medium. The plates were then incubated overnight at $37^{\circ} \mathrm{C}$. Next day, the total diameter of the zone of inhibition was recorded in $\mathrm{mm}$. The result was interpreted as per standard guidelines (CLSI, 2015).

\section{Phenotypic detection of carbapenam resistant $E$. coli}

Phenotypic carbapenem resistant isolates were detected by Kirby Bauer disc diffusion method (CLSI, 2015) using 10 $\mathrm{g}$ disc of ertapenem, meropenem, imipenem and doripenem.

\section{Phenotypic detection of ESBL producing} $E$. coli by combination disc method

All the E. coli isolates were inoculated in Luria Bertani (LB) broth for overnight incubation at $37^{\circ} \mathrm{C}$. The bacterial inoculums were standardized by measuring the optical density (O.D) at $600 \mathrm{~nm}$ wavelength to 0.5 McFarland standards. The bacterial lawn was prepared on MHA plates and subsequently discs of ceftazidime $(30 \mu \mathrm{g})$, and cefotaxime $(30 \mu \mathrm{g})$ were diagonally placed with the corresponding discs of ceftazidime + clavulanic acid $(30 / 10 \mu \mathrm{g})$ and cefotaxime + clavulanic acid $(30 / 10 \mu \mathrm{g})$, respectively. An increase of $5 \mathrm{~mm}$ or more in the zone of inhibition of disc containing the antibiotic along with clavulanic acid than the disc containing the antibiotic alone was indicative of ESBL producer (fig.1).

\section{Results and Discussion}

\section{Isolation and identification of $E$. coli}

Out of 102 fecal samples, 14 were diarrhoeic samples and all were positive for E. coli. The pink colour colony on MAC Agar indicating the lactose fermenter (fig. 2) when further streaked on EMB showed characteristics green metallic sheen (fig.3) which was further characterized by biochemical kit (fig. 4). E. coli is Indole and MR positive and VP and Citrate negative, Carbohydrate utilization test result was glucose + , adonitol-, arabinose+, lactose+, sorbitol+, mannitol+, rhamnose- $\mathrm{V}$, sucrose $-\mathrm{V}$ (variable). On the basis of microbiological and biochemical analysis, all the fecal samples were found positive for the E. coli i.e. isolation rate was $100 \%$.

\section{Molecular characterization}

Out of $102 \mathrm{E}$. coli isolates 80 were positive for uspA gene (fig.5). E. coli isolated from diarrhoeic samples was all positive for uspA gene. There was difference of $21.57 \%$ in phenotypic and genotypic expression of $E$. coli isolates.

\section{Antibacterial drug resistance profiling of the $E$. coli isolates}

\section{Antibiogram of $E$. coli isolates}

Antibiotic susceptibility pattern of the $102 \mathrm{E}$. coli isolates were determined by Kirby Bauer disc diffusion method against 16 different antibiotics (fig.6). The overall resistance (resistant + intermediate) was maximum against kanamycin (97\%) followed by tetracycline $(68.6 \%)$, ceftazidime $(63.7 \%)$, Nitroflurantoin (52\%) ampicilin (51\%), trimethoprime $(47 \%)$, streptomycin $(44.1 \%)$ co-trimoxazole and sulphadiazine (42\%). Maximum sensitivity was observed against gentamicin (94.14\%) and colistin (93.1\%), 
followed by ciprofloxacin $(81.4 \%)$, ofloxacin $(77.5 \%)$ and amikacin (69.6\%) (Table 2; Fig. 7). There was wide spread multidrug resistance among the E. coli isolates, $83.33 \%$ $(85 / 102)$ of isolates were multi-drug resistant i.e. resistant against 3 or more antibiotics.

\section{ESBL producing $E$. coli}

A total of $39(38.24 \%)$ isolates were phenotypic ESBL producer. Prevalence of ESBL among healthy calves was $32.95 \%$ (29/88), whereas among diarrheic calves was $71.43 \%(10 / 14)$.

\section{Carbapenem resistant $E$. coli}

Out of the 102 isolates, $22(21.57 \%)$ were found to be carbapenem resistant. Carbapenem resistance was $21.6 \%(19 / 88)$ from healthy calves, whereas from that of diarrheic calves it was just $13.64 \%$ (3/22).

Among the carbapenem, maximum resistance was seen against ertapenem (14/22), and meropenem, imipenem and doripenem resistant isolates were two each $(2 / 22)$.

\section{Neonatal calf mortality}

Neonatal diseases and mortality among cattle and buffalo is the major cause of economic losses in the livestock sector (Singh et al., 2009). High morbidity and mortality during neonatal period is primarily due to diarrhea (De la Fuente et al., 1999; Svensson et al., 2006). E. coli is considered as the most common bacterial cause of neonatal diarrhea. In the present study, all the 102 fecal samples (88 healthy and 14 diarrhoeic samples) were positive for $E$. coli. A similar finding was reported by the Ibrahim (1995). Hemashenpagam et al., (2009) in India reported $75 \%$ prevalence, whereas Malik et al., (2012) and Joon and Kaura (1993) reported much less prevalence $(37 \%$ and $23 \%$ ). The differences in the prevalence rates of $E$. coli among diarrheic calves may be attributed to the geographical locations of the farm, management practice and hygienic measures (El-Seedy et al., 2016). Therefore, it is imperative to study the prevalence of enteropathogens and related risk factors which can modulate the occurrence of diarrhoea among calves.

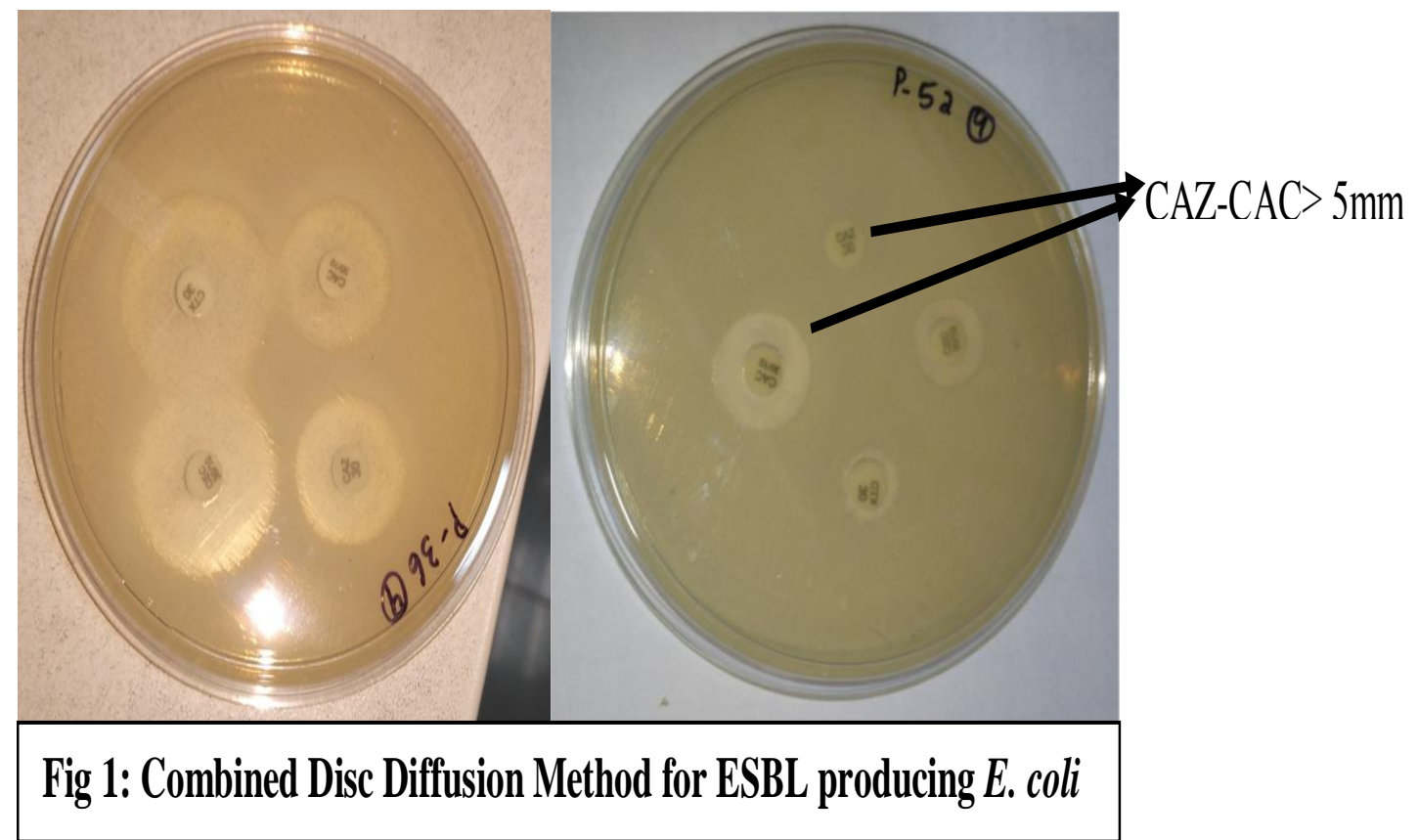



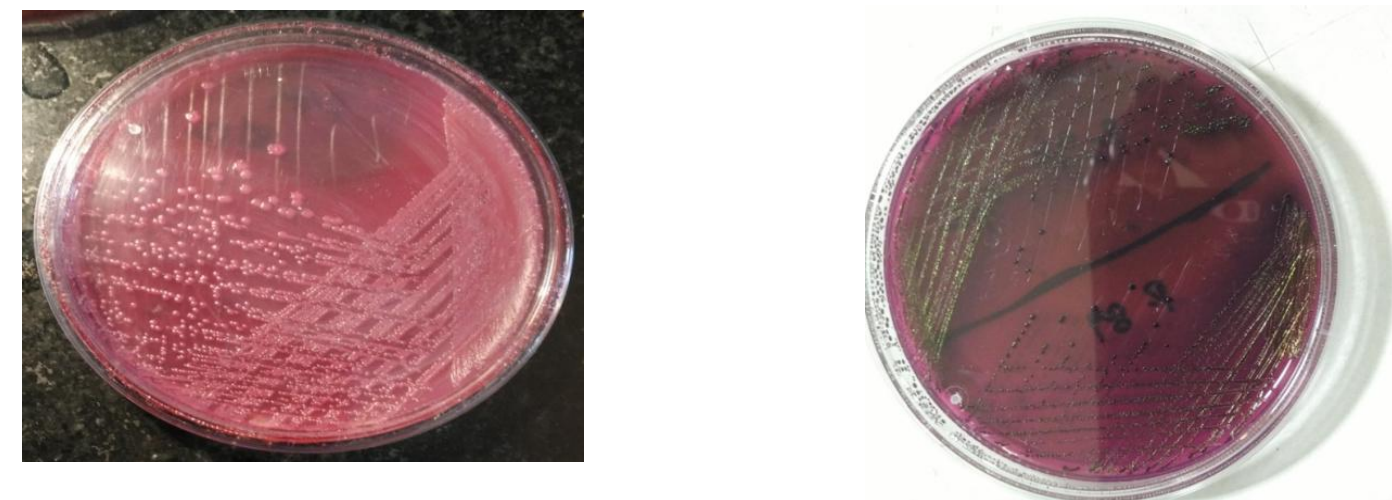

Fig.2 Pink colour colonies of E.coli on MAC

Fig.3 Green metallic sheen of E.coli on EMB Agar
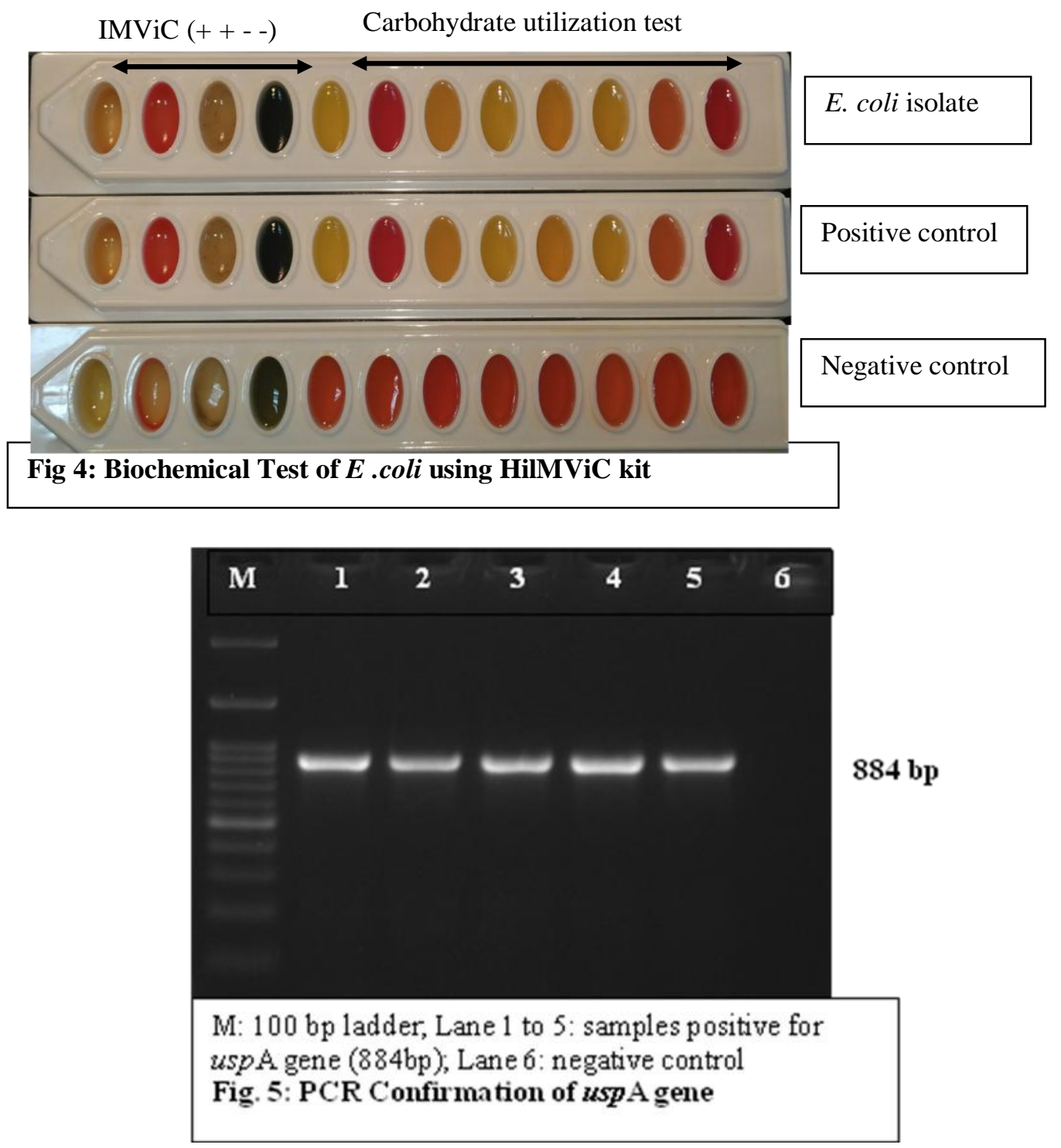


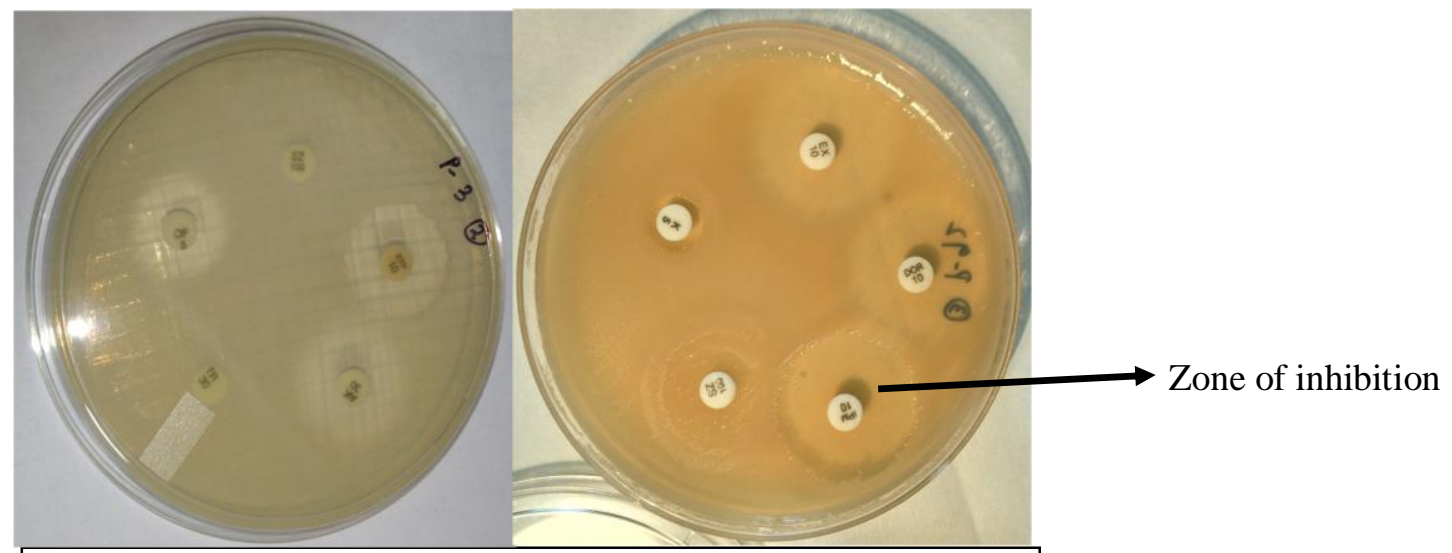

Fig. 6: Kirby Bauer disc diffusion method

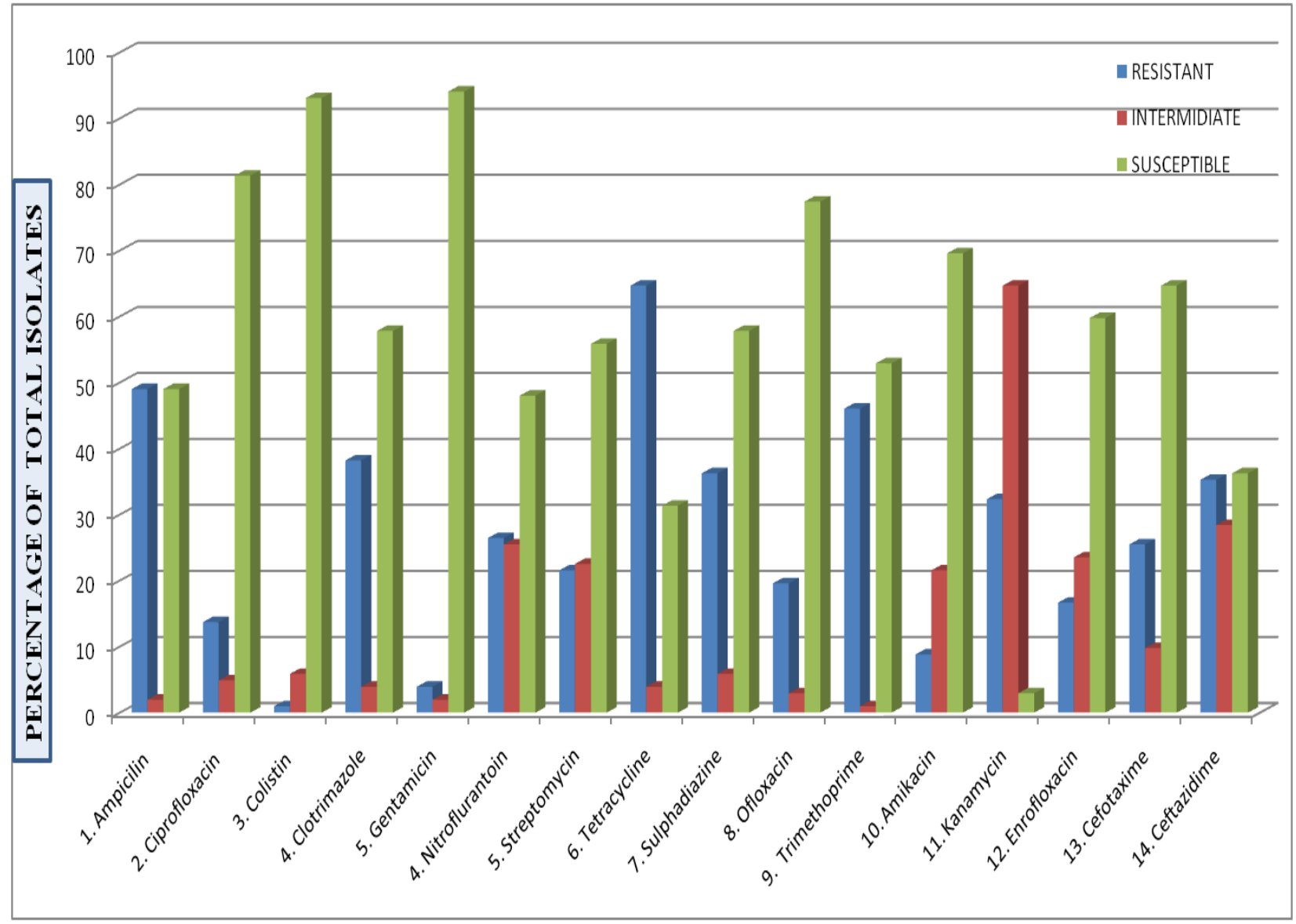

Fig. 7 : Antibiogram of $E$. coli 
Table.1 PCR conditions for detection of uspA gene

\begin{tabular}{|l|l|l|l|}
\hline PCR steps & Temperature & Duration & Cycles \\
\hline Initial denaturation & $95^{\circ} \mathrm{C}$ & $2 \mathrm{~min}$ & 1 \\
\hline Denaturation & $94^{\circ} \mathrm{C}$ & $30 \mathrm{sec}$ & 30 \\
\hline Annealing & $58^{\circ} \mathrm{C}$ & $60 \mathrm{sec}$ & 30 \\
\hline Extension & $72^{\circ} \mathrm{C}$ & $60 \mathrm{sec}$ & 30 \\
\hline Elongation & $72^{\circ} \mathrm{C}$ & $5 \mathrm{~min}$ & 1 \\
\hline Cooling & $4^{\circ} \mathrm{C}$ & Infinite & \\
\hline
\end{tabular}

Table.2 Antibiotic susceptibility profile of E. coli isolates

\begin{tabular}{|l|l|l|l|}
\hline & \multicolumn{3}{l}{ Percentage of isolates } \\
\cline { 2 - 4 } & Resistant & Intermediate & Susceptible \\
\hline Ampicilin (AMP-10) & 49.02 & 1.96 & 49.02 \\
\hline Ciprofloxacin (CIP5) & 13.72 & 4.9 & 81.34 \\
\hline Colistin (CL-10) & 0.98 & 5.88 & 93.1 \\
\hline Clotrimazole (COT25) & 38.22 & 3.92 & 57.82 \\
\hline Gentamicin (GEN10) & 3.92 & 1.96 & 94.08 \\
\hline Nitroflurantoin (NIT10) & 26.46 & 25.48 & 48.02 \\
\hline Streptomycin (S10) & 21.56 & 22.54 & 55.86 \\
\hline Tetracycline (TE30) & 64.68 & 3.92 & 31.36 \\
\hline Sulphadiazine (SZ100) & 36.26 & 5.88 & 57.82 \\
\hline Ofloxacin (OF5) & 19.6 & 2.94 & 77.42 \\
\hline Trimethoprime (TR) & 46.06 & 0.98 & 52.92 \\
\hline Amikacin (AK30) & 8.82 & 21.56 & 69.58 \\
\hline Kanamycin (K30) & 32.34 & 64.68 & 2.94 \\
\hline Enrofloxacin (EX10) & 16.66 & 23.52 & 59.78 \\
\hline Cefotaxime (CTX30) & 25.48 & 9.8 & 64.68 \\
\hline Ceftazidime (CAZ30) & 35.28 & 28.42 & 36.26 \\
\hline
\end{tabular}

\section{Molecular confirmation by usp A gene}

In present study $78.43 \%$ of the total isolates harvested usp A gene which is a universal stress protein specific for $E$. coli. There was difference of $21.57 \%$ in phenotypic and genotypic expression of $E$. coli isolates. Usp A is essential for the bacteria to cope with the cellular defence mechanism and oxidative stress (Nachin et al., 2005; Siegle, 2005). It can also be targeted for many immunological assays, and can be included as a candidate for multiple subunit vaccines. In a study
Godambe et al., (2017) stated that two molecular markers (uid A and flanking region of $u s p \mathrm{~A}$ ) along with microbiological method were specific for the E. coli, in which $77 \%$ of the isolates were positive for both the genes but, $22 \%$ of the E. coli isolates were positive for any one of the two genes. In contrast, Molina et al., (2015) stated that yaiO and lacZ3 primers are unique to $E$. coli, unfortunately these were not tested in field. Although, molecular confirmation is better than phenotypic detection, there are possibilities that molecular detection based on 
one marker gene may give false negative results. PCR based confirmation of typical and atypical colonies obtained on selective plate for $E$. coli would give much accurate result.

\section{Antimicrobial resistance}

Extensive use of antibiotics in animal husbandry and veterinary practices at subtherapeutic levels for growth promotion, prophylaxis and treatment had led to the development of antibiotic resistance in bacteria (Wileman et al., 2009). Antimicrobial resistance is an increasing global threat to both human and animal health (Tadesse et al., 2012; WHO, 2012). In present study, Antibiogram pattern was recorded against 16 different antibiotics revealed $83.33 \%$ (85/102) were MDR. The overall resistance was maximum against kanamycin $(97 \%)$ followed by tetracycline (68.6\%), ceftazidime $(63.7 \%)$, Nitroflurantoin $(52 \%)$ ampicilin (51\%), trimethoprime (47\%), streptomycin $(44.1 \%)$ co-trimoxazole and sulphadiazine (42\%). Maximum sensitivity was observed against gentamicin $(94.14 \%)$ and colistin (93.1\%), followed by ciprofloxacin (81.4\%), ofloxacin $(77.5 \%)$ and amikacin (69.6\%). A study on antimicrobial susceptibility of $96 \mathrm{E}$. coli isolates recovered from diarrheic calves of less than 3 months of age revealed high resistance against all antibiotics except for marbofloxacin, spectinomycin and neomycin (El seedy et al., 2016). Khachatryan et al., (2004) hypothesized that neonate-adapted bacteria were responsible for the high frequencies of resistant E. coli. Another study conducted in Uttar Pradesh, India by Malik et al., (2012) reported higher sensitivity to amikacin $(87.80 \%)$ and gentamicin $(51.21 \%)$ and antimicrobial resistant profile was similar to our findings. However, 100\% resistance were recorded against ampicillin, co-trimoxazole, erythromycin, and tetracycline. Shahrani et al., (2014) reported high resistance to penicillin (100\%), streptomycin (98.25\%) and tetracycline (98.09\%). Ansari et al., (2014) reported similar type of findings where $100 \%$ resistant was observed against amoxycillin and tetracycline, $80 \%$ to Carbinicillin, $60 \%$ to cefotaxime and $20 \%$ to bacitracin and erythromycin. Ibrahim et al., (2016) observed high resistance against ampicillin $(56.3 \%)$, and low resistance against imipenem (1.6\%).

There is a worldwide increase in the extended-spectrum $\beta$-lactamases (ESBLs) in Enterobacteriacae, particularly E. coli. The use of third generation cephalosporin's (cefotaxime, ceftazidime, ceftriaxone) in human medicine is generally believed to have been a major selective force in the emergence of ESBLs. In the present study, 39 (38.24\%) isolates were ESBL producers $(32.95 \%$ from healthy and $71.43 \%$ from diarrheic calves), and $22(21.57 \%)$ were carbapenem resistant; $21.6 \%(19 / 88)$ from healthy calves and 13.64 $\%(3 / 22)$ from diarrheic calves. Among the carbapenem, maximum resistance was seen against ertapenem (14/22), and remaining meropenem, imipenem and doripenem resistant isolates were two each $(2 / 22)$.

One possible reason for such a wide spread resistance may be intrinsic or acquired through spontaneous mutations (de novo), or may occur due to horizontal gene transfer from donor bacteria, phages, or free DNA (Dodd, 2012). Due to horizontal gene transfer even nonpathogenic microbial species that harbour resistant genes serve as an ecological reservoir for pathogenic bacteria (Salyers and Shoemaker, 2006). These mechanisms include the uptake of naked DNA and mobile genetic elements such as plasmids, transposons, integrons, gene cassettes, and bacteriopahges (Nwosu, 2001).

It can be concluded from the present study that; both diarrhoeic and normal calves 
harvested MDR E. coli which was around $83 \%(85 / 102)$ isolates. $80 / 102$ isolates were positive for specific uspA gene. 39 (38.24\%) isolates were phenotypic ESBL producers and $22(21.57 \%)$ isolates were phenotypic carbapenem resistant. The increasing trends of multiple drug resistance among $E$ coli isolates from neonatal calves are of utmost concern. The large number of calves dies during pre-weaning age causing heavy loss to livestock production and in turn to economy. Hence, surveillance based study, antimicrobial resistance profiling and search for an alternative to antibiotics is the need of hour to address the global issue of the antimicrobial resistance.

\section{Acknowledgments}

The work presented here was carried out at the Division of Bacteriology and Mycology of Indian Veterinary Research Institute, Bareilly. The infrastructure and facilities created under the ICAR-IVRI Bareilly is thankfully acknowledged. The research work was supported by the funding received under "ICAR All India Network programme on Neonatal Mortality in Farm Animals"

\section{References}

Aarestrup, F.M. and Wegener, H.C., 1999. The effects of antibiotic usage in food animals on the development of antimicrobial resistance of importance for humans in Campylobacter and Escherichia coli. Microbes and infection, 1(8), pp.639- 644.

Allen, H.K., Donato, J., Wang, H.H., CloudHansen, K.A., Davies, J. and Handelsman, J., 2010. Call of the wild: antibiotic resistance genes in natural environments. Nature Reviews Microbiology, 8(4), pp.251-259.

Ansari, R.A.I.H., Rahman, M.M., Islam, M.Z., Das, B.C., Habib, A., Belal,
S.M.S.H. and Islam, K., 2014. Prevalence and antimicrobial resistance profile of Escherichia coli and salmonella isolated from diarrheic calves. Journal of Animal Health and Production, 2(1), pp.12-15

Ashbolt, N.J., Amézquita, A., Backhaus, T., Borriello, P., Brandt, K.K., Collignon, P., Coors, A., Finley, R., Gaze, W.H., Heberer, T. and Lawrence, J.R., 2013. Human health risk assessment (HHRA) for environmental development and transfer of antibiotic resistance. Environmental health perspectives, 121(9), p.993

Bergey's Manual, 1995

Blowey, R.W. 1990. Veterinary Book for Dairy Farmers. 2nd ed. Ipswich: Farming press Ltd.

De la Fuente, R., Luzon, M., Ruiz-SantaQuiteria, J.A., García, A., Cid, D., Orden, J.A., Garcia, S., Sanz, R. and Gomez-Bautista, M., 1999. Cryptosporidium and concurrent infections with other major enterophatogens in 1 to 30-day-old diarrheic dairy calves in central Spain. Veterinary parasitology, 80(3), pp.179185

Dodd, M.C., 2012. Potential impacts of disinfection processes on elimination and deactivation of antibiotic resistance genes during water and wastewater treatment. Journal of Environmental Monitoring, 14(7), pp.1754-1771

El-Seedy, F.R., Abed, A.H., Yanni, H.A. and El-Rahman, S.A., 2016. Prevalence of Salmonella and E. coli in neonatal diarrheic calves. Beni-Suef University Journal of Basic and Applied Sciences, 5(1), pp.45-51

Godambe, L.P., Bandekar, J. and Shashidhar, R., 2017. Species specific PCR based detection of Escherichia coli from Indian foods. 3 Biotech, 7(2), p.130.

Hemashenpagam, N., Kiruthiga, B., Selvaraj, 
T. and Panneerselvam, A., 2009. Isolation, identification and characterization of bacterial pathogens causing calf diarrhoea with special reference to Escherichia coli. Int. J. Microbiol, 7(2), pp.1-4.

Ibrahim, D.R., Dodd, C.E., Stekel, D.J., Ramsden, S.J. and Hobman, J.L., 2016. Multidrug resistant, extended spectrum $\beta$-lactamase (ESBL)-producing Escherichia coli isolated from a dairy farm. FEMS microbiology ecology, 92(4).

Joon, D. S. and Kaura, Y. K. 1993. Isolation and characterization of some of the enterobacteria from diarrhoeic and nondiarrhoeic calves. Indian J. Anim. Sci, 63:373-383.

Khachatryan, A.R., Hancock, D.D., Besser, T.E. and Call, D.R., 2004. Role of calfadapted Escherichia coli in maintenance of antimicrobial drug resistance in dairy calves. Applied and environmental microbiology, 70(2), pp.752-757.

Levine, M. M., Kaper, J. B., Black, R. E. and Clements, M. L. 1987. New knowledge on pathogenesis of bacterial enteric infections as applied to vaccine development. Microbiol. Rev., 47: 510550.

Lorenz, I., Fagan, J., and More, S.J. 2011. Calf health from birth to weaning. II. Management of diarrhoea in preweaned calves. Irish. Vet. J. 64:

Malik, S., Verma, A.K., Kumar, A., Gupta, M.K. and Sharma, S.D., 2012. Incidence of calf diarrhea in cattle and buffalo calves in Uttar Pradesh, India. Asian Journal of Animal and Veterinary Advances, 7(10), pp. 1049-1054

Mishra, A.K., Singh, D.D., Kumarsen, G., Gupta, G., Sharma, N., Kumar, N., Nayakvadi, S. and Paul, S., 2017. UspA Gene Based Characterization of Escherichia coli Strains Isolated from
Different Disease Conditions in Goats. Journal of Animal Research, 7(6), pp.1123-1128.

Molina F, López-Acedo E, Tabla R, Roa I, Go'mez A, Rebollo JE (2015) Improved detection of Escherichia coli and coliform bacteria by multiplex PCR. BMC Biotechnol 4:15-48

Muktar, Y., Mamo, G., Tesfaye, B. and Belina, D., 2015. A review on major bacterial causes of calf diarrhea and its diagnostic method. Journal of Veterinary Medicine and Animal Health, 7(5), pp.173-185.

Nachin, L., Nannmark, U. and Nyström, T. 2005. Differential roles of the universal stress proteins of Escherichia coli in oxidative stress resistance, adhesion, and motility. J. Bacteriol., 187(18): 6265-6272.

Nwosu, V.C., 2001. Antibiotic resistance with particular reference to soil microorganisms. Research in Microbiology, 152(5), pp.421-430.

Nyström, T. and Neidhardt, F.C. 1992. Cloning, mapping and nucleotide sequencing of a gene encoding a universal stress protein in Escherichia coli. Mol. Microbiol., 6: 3187-3198.

Nystrom, T. and Neidhardt, F.C. 1993. Isolation and properties of a mutant of Escherichia coli with an insertional inactivation of the UspA gene, which encodes a universal stress protein. $J$. Bacteriol., 175:3949-3956.

Osek, J., 2001. Multiplex polymerase chain reaction assay for identification of enterotoxigenic Escherichia coli strains. J. Vet. Diagn. Invest, 13(4): 308-311.

Rajput, S.K., Gururaj, K., Tiwari, U. and Singh, G. 2014. Study of the characterization of $E$. coli isolates in goat kids. Indian Res. J. Genet. Biotech, 6(1): 324-329.

Salyers, A. and Shoemaker, N.B., 2006. Reservoirs of antibiotic resistance 
genes. Animal biotechnology, 17(2), pp.137-146.

Shahrani, M., Dehkordi, F.S. and Momtaz, H., 2014. Characterization of Escherichia coli virulence genes, pathotypes and antibiotic resistance properties in diarrheic calves in Iran. Biological research, 47(1), p. 28.

Siegele, D.A. 2005. Universal stress proteins in Escherichia coli. J. Bacteriol., 187(18): 6253-6254.

Singh, D.D., Kumar, M., Choudhary, P.K. and Singh, H.N., 2009. Neonatal calf mortality- an overview. Intas Polivet, 10(2), pp.165-169

Stobberingh, E.E. and Van den Bogaard, A.E., 2000. Spread of antibiotic resistance from food animals to man. Acta Veterinaria Scandinavica. Supplementum (Denmark).

Svensson, C., J. Hultgren, and P. A. Oltenacu. 2006. Morbidity in 3-7-month-old dairy calves in south-western Sweden, and risk factors for diarrhoea and respiratory disease. Prev. Vet. Med. 74:162-179.

Tadesse, D.A., Zhao, S., Tong, E., Ayers, S., Singh, A., Bartholomew, M.J. and McDermott, P.F., 2012. Antimicrobial drug resistance in Escherichia coli from humans and food animals, United States, 1950-2002. Emerging infectious diseases, 18(5), p.741.

Tenaillon, O., Skurnik, D., Picard, B. and Denamur, E., 2010. The population genetics of commensal Escherichia coli. Nature Reviews Microbiology, 8(3), pp. 207-217.

Wileman, B.W., Thomson, D.U., Reinhardt, C.D. and Renter, D.G., 2009. Analysis of modern technologies commonly used in beef cattle production: Conventional beef production versus nonconventional production using metaanalysis. Journal of animal science, 87(10), pp.34183426.

\section{How to cite this article:}

Shailendri Gupta, Abhishek, Sameer Shrivastava and Asha K. Verma. 2019. Isolation, Identification, Molecular Characterization and Antibiogram of $E$. coli Isolates from Neonatal Calves. Int.J.Curr.Microbiol.App.Sci. 8(06): 1996-2007. doi: https://doi.org/10.20546/ijcmas.2019.806.238 